\title{
METHOD OF DISCRETENESS SUBSTANTIATION OF QUALITATIVE CHARACTERISTICS TESTING DURING IRON ORE RAW MATERIALS EXTRACTION
}

\author{
Volodymyr Azarian ${ }^{1}$
}

Received: 2021-06-11

Accepted: 2021-07-02

DOI: http://doi.org/10.46489/gpj.2021-1-2-1

\begin{abstract}
The article aims to substantiate the periodicity of the definition of the maintenance of a valuable component in faces. Information about the content of the valuable component is necessary to comply with the requirements of the enrichment complex while ensuring the process of the total cargo flow formation. Traditionally, in iron ore quarries, technical control services measure the content of the valuable component every shift, but the testing period requires determination. We aimed to justify the period of testing the quality characteristics of iron ore. To achieve the aim, we explored the quarry № 3 of the PJSC "ArcelorMittal Kryvyi Rih" Mining Department based on the provisions of the mining theory and using mathematical modelling and mathematical statistics methods. We developed a method of substantiating the period of testing the qualitative characteristics of the faces, which we checked based on data from the existing enterprise. Using our method, we proved the possibility of increasing the test period without losing the necessary information about the iron content and without reducing the quality characteristics of the formed final ore flow. Increasing the test period will help companies decrease costs by reducing the number of visits of technical control specialists to test the quarry face. The proposed technique can be helpful to any mining company that supports the data collection and maintain the statistical database of measurements of the valuable component content.
\end{abstract}

Keywords: valuable component content, ore freight flow, iron ore quality management, mining industry, testing period

\footnotetext{
${ }^{1}$ Volodymyr Azarian, D.Sc. (Technical Sciences), Professor, Professor of Department of Opencast Mining, Kryvyi Rih National University, Pushkina Str., 37, Kryvyi Rih, 50000, Ukraine, astp165@ukr.net, ORCID: https://orcid.org/0000-0001-9045-509X
} 


\section{ВСТУП}

Формування загального рудопотоку із заданими показниками якості здійснюється на підставі розподілу обсягів видобутку між забоями 3 різними показниками вмісту корисного компоненту (Byzov, V.F., Vilkul, Ju.G., Maksimov, I.I., 1982). При розв'язанні шихтувального завдання першим припущенням $\epsilon$ те, що забої починають роботу одночасно та працюють всю зміну без зупинок. Другим припущенням $\epsilon$ константне значення вмісту корисного компонента в забої впродовж всієї зміни. Насправді, в реальних умовах за період виробничої зміни відбуваються суттєві відхилення від початкового розрахунку, які впливають на формування якісних характеристик загального інтегрованого рудопотоку та амплітуду ï коливань. Зумовлюються ці відхилення багатьма факторами: неодночасністю початку роботи по забоях, поломками устаткування та природною динамікою зміни вмісту корисного компонента в кожному видобувному забої. Для усунення дисбалансу між розрахунковими i фактичними значеннями якості необхідно періодично виконувати коригувальний перерахунок у шихтувальному завданні. Після цього навантаження на забої перерозподіляються 3 урахуванням поточного значення вмісту корисного компоненту та працездатності обладнання.

Фактичні значення вмісту корисного компоненту в кожному забої визначаються методами оперативного контролю. Для отримання своєчасної та достовірної інформації про стан якісних характеристик у забоях необхідно, 3 урахуванням динаміки зміни вмісту корисного компоненту, обгрунтувати інтервал опробування.

У залізорудних кар'єрах служби технічного контролю виконують опробування у забоях щозміни, використовуючи наявну апаратурну базу пристроїв. При цьому виходять, перш за все, з технічних можливостей цих пристроїв по контролю якості. Але сам період зняття інформації про вміст корисного компонента (дискретність опробування) - математично i технологічно не обгрунтований (Babij, E.V., Sinenko, M.A., 2010). Тому метою досліджень визначено розробку методики обгрунтування дискретності опробування якісних характеристик залізорудної сировини на основі існуючих статистичних даних. Визначений період опробування дозволить отримувати більш достовірну та своєчасну інформацію про фактичні значення вмісту корисного компонента в забоях, які в подальшому будуть використані для розрахунку змінно-добового завдання 3 метою формування загального інтегрованого рудопотоку 3 відповідними показниками якості.

Для обгрунтування дискретності опробування якісних характеристик залізорудної сировини в забоях 3 використанням статистичних даних було застосовано теорії гірничої справи, методи математичного моделювання, математичної статистики та графічний аналіз.

Для проведення розрахунку використовувались результати вимірів вмісту заліза магнітного в руді кар'єру № 3 Гірничого департаменту ПАТ «АрселорМіттал Кривий Ріг» екскаваторами №№ 56, 23 та 97.

\section{РЕЗУЛЬТАТИ}

Похибка вимірювання, як i особливості технологічних процесів при видобутку залізної руди, вказують на можливість обліку зміни вмісту корисного компоненту 3 визначеною дискретністю. Це приводить до висновку про можливість вимірювання якості в забоях з певним періодом, та 
розглядати рудний вантажопотік як дискретний часовий ряд.

Згідно із загальним підходом для чисельного аналізу вмісту корисного компонента в руді, виміри цього вмісту $\mathrm{c}(\mathrm{t})$, як безперервного в часі, необхідно здійснювати через деякий фіксований інтервал $\Delta$. Отримані таким чином дискретизовані значення будуть потім використовуватися для подальших обчислень змінно-добових завдань.

Дискретизовані значення можна розглядати як результат множення початкового безперервного часового ряду $\mathrm{c}(\mathrm{t})$ на часовий ряд $\mathrm{i}(\mathrm{t})$, що складається 3 нескінченної низки дельта-функцій (Rodionov, I.B., 2011):

$$
i(t)=\sum_{n=-\infty}^{\infty} \delta(t-n \Delta),
$$

де $\delta(t)=\left\{\begin{array}{ll}0, & t \neq 0 \\ \infty, & t=0\end{array}\right.$.

Це дає можливість відобразити корисного компонента в руді: імпульсно-модульований вміст

$$
c_{i}(t)=c(t) i(t) .
$$

Користуючись теоремою про формули (2) в частотній області: згортку, знаходимо подання

$$
C_{i}(f)=\int_{-\infty}^{\infty} C(f-g) I(g) d g,
$$

де $C(f), I(f)-$ перетворення Фур'є від

$c(t)$ та ${ }^{i(t)}$, відповідно. Враховуючи, що

$$
I(g)=\frac{1}{\Delta} \sum_{n=-\infty}^{\infty} \delta\left(g-\frac{n}{\Delta}\right),
$$

формула (3) перетвориться до

вигляду

$$
C_{i}(f)=\int_{-\infty}^{\infty} C(f-g) \frac{1}{\Delta} \sum_{n=-\infty}^{\infty} \delta\left(g-\frac{n}{\Delta}\right) d g=\frac{1}{\Delta} \sum_{n=-\infty}^{\infty} C\left(f-\frac{n}{\Delta}\right) .
$$

Рівність (5) показує, що імпульсномодульований вміст корисного компонента в руді с (t) $\epsilon$ перетворенням

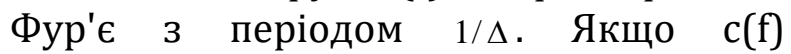
обертається на нуль при $|f| \geq 1 /(2 \Delta)$, то

$$
H(f)=\left\{\begin{array}{l}
\Delta,|f| \leq \frac{1}{2 \Delta} \\
0,|f|>\frac{1}{2 \Delta}
\end{array} .\right.
$$

Функція (6) є спектральним вікном і вона знаходиться, як перетворення

$$
h(t)=\frac{\Delta}{\pi \cdot t} \sin \left(\frac{\pi \cdot t}{\Delta}\right) .
$$

Так як множенню в частотній області відповідає згортка в часовій області, то, 3 урахуванням

$$
c(t)=\frac{\Delta}{\pi} \int_{-\infty}^{\infty} \frac{1}{u} \sin \left(\frac{\pi \cdot u}{\Delta}\right) \cdot c_{i}(t-u) d u .
$$

Частота $\quad f_{N}=1 /(2 \Delta) \quad$ називається частотою Найквіста-Котельникова і $\epsilon$ найвищою частотою, яку можна виявити за даними, отриманими 3 інтервалом відліку $\Delta$. 
Для аналізу часового ряду, складеного 3 вмісту корисного компоненту в руді, 3 метою обгрунтування періоду вимірювання спектральні властивості цього ряду, що спираються на властивості якості у забоях кар'єру, треба дослідити

автокореляційної функції і нормованого спектра.

Відомо, що автокореляційна функція є залежністю взаємозв'язку між функцією та її здвигнутою копією від величини часового здвигу. Якщо автокореляційна функція оцінюється за формулою

$$
r_{k}=\frac{d_{k}}{d_{0}}
$$

де $d_{k}=\frac{1}{N} \sum_{i=1}^{N-k}\left(c_{i}-\bar{c}\right)\left(c_{i+k}-\bar{c}\right), \quad \bar{c}=\frac{1}{N} \sum_{i=1}^{N} c_{i}$, $k=0,1,2, \ldots, K$, то вибірковий нормований

$$
S(f)=2\left(1+2 \sum_{k=1}^{K-1} r_{k} \cos (2 \pi \cdot f \cdot k)\right), \quad 0 \leq f \leq 0,5
$$

Відомо, що вибірковий нормований спектр - це косинус-перетворення Фур'є вибіркової автокореляційної функції. Аналізуючи графік, побудований за допомогою вибіркового нормованого спектра (10), можна оцінити розподіл дисперсії часового ряду за частотами (Gmurman, V.E., 1975).
На рис. 1 наведено результати вимірів вмістів заліза магнітного в руді, що добувається в кар'єрі № 3 Гірничого департаменту ПАТ «АрселорМіттал Кривий Ріг» екскаваторами №№ 56, 23 та 97. Опробування видобувних забоїв виконувалися зі інтервалом у 12 годин.

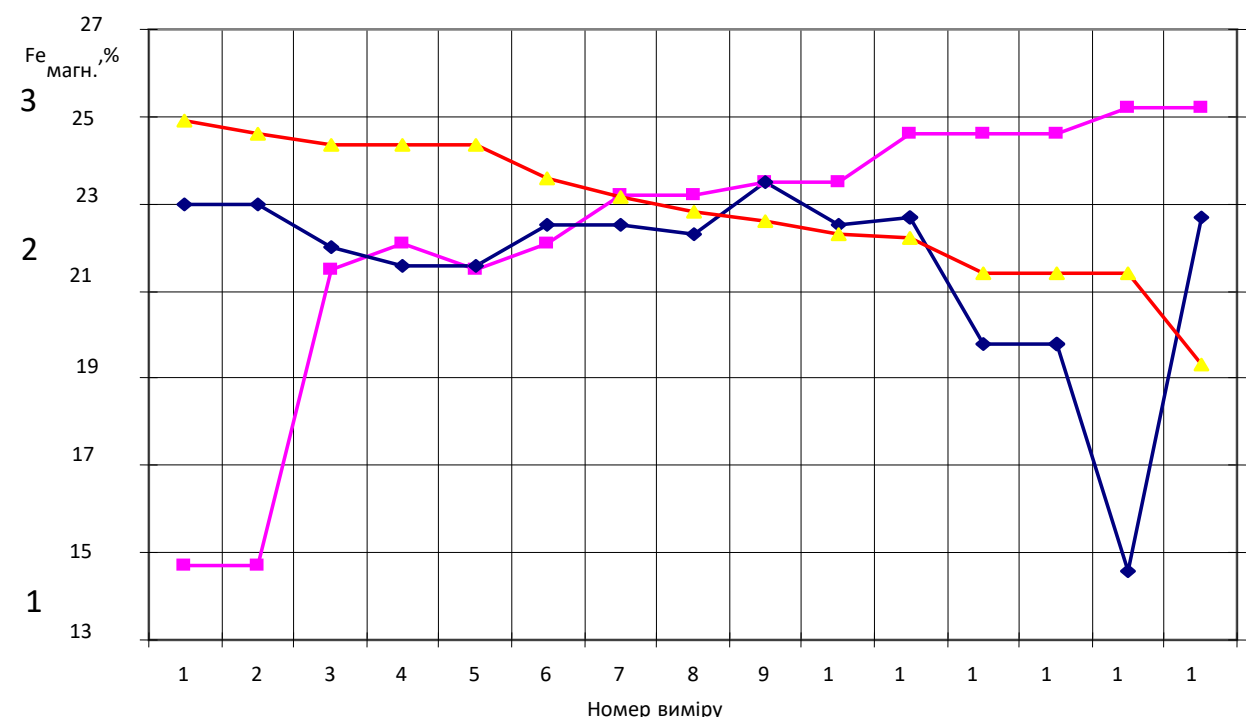

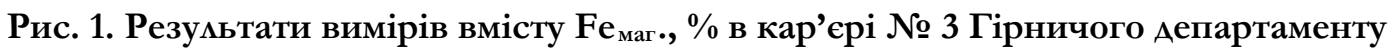

ПАТ «АрселорМіттая Кривий Ріп»: 1 - екскаватор № 56, 2 - екскаватор № 23, 3 - екскаватор № 97

Якщо значення дисперсії будуть сконцентровані на низьких частотах, що менші за частоти НайквістаКотельникова $f_{N}$, то дискретність опробування можна збільшити.

Розглянемо приклад обгрунтування періоду опробування забоїв кар'єру на підставі наявної статистики вимірів вмісту корисного компоненту кар'єру № 3 Гірничого департаменту ПАТ «АрселорМіттал Кривий Ріг».

У табл. 1 наведені значення вибіркових автокореляційних функцій, розрахованих за формулою (9) для забоїв екскаваторів №№ 56, 23 та 97 
кар’єру № 3 Гірничого департаменту

ПАТ «АрселорМіттал Кривий Ріг».

Таблиця 1

Значення вибіркових автокореляційних функций Аля забоїв екскаваторів №№ 56, 23 та 97 кар’еру № 3 Гірничого департаменту ПАТ «АрселорМіттах Кривий Ріг»

\begin{tabular}{|c|c|c|c|}
\hline $\begin{array}{c}\text { № } \\
\text { екскаватора }\end{array}$ & 93 & 56 & 23 \\
\hline 1 & 0,67 & 0,57 & 0,73 \\
\hline 2 & 0,41 & 0,42 & 0,51 \\
\hline 3 & 0,37 & 0,42 & 0,36 \\
\hline 4 & 0,15 & 0,34 & 0,19 \\
\hline 5 & 0,04 & 0,33 & 0,21 \\
\hline 6 & $-0,21$ & 0,43 & 0,20 \\
\hline 7 & -0.24 & 0,50 & 0,04 \\
\hline
\end{tabular}

На рис. 2, 3 та 4 наведено графіки вибіркових автокореляційних функцій вмісту заліза магнітного в забоях

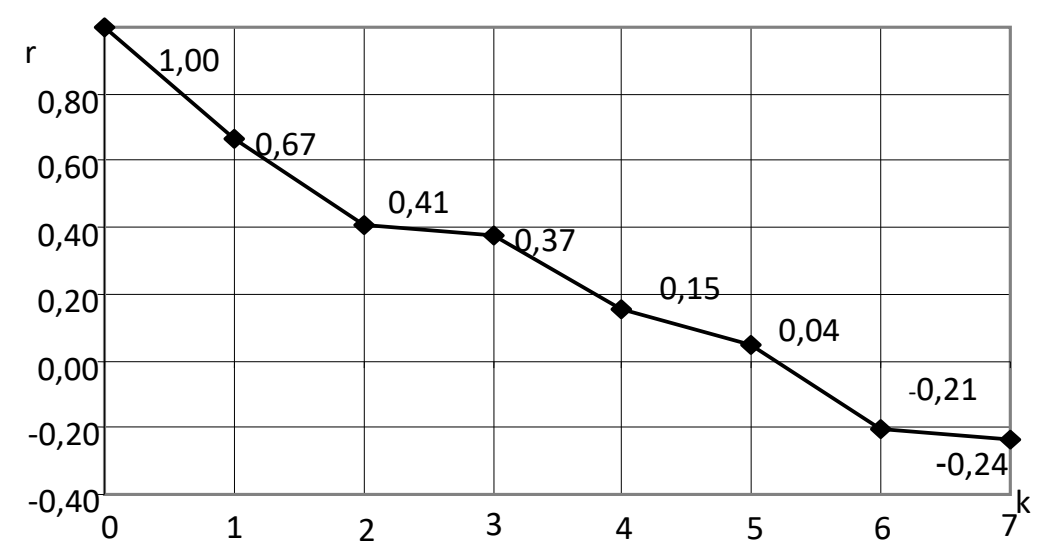

Рис. 2. Вибіркова автокоремяційна функція вмісту заліза магнітного в забої екскаватору № 93

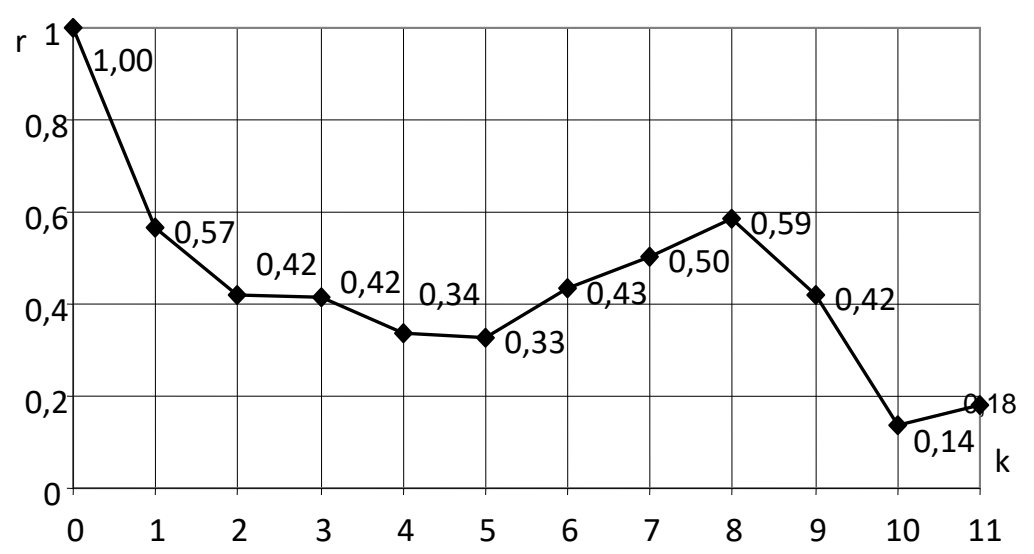

Рис. 3. Вибіркова автокоремяційна функція вмісту заліза магнітного в забої екскаватору № 56 


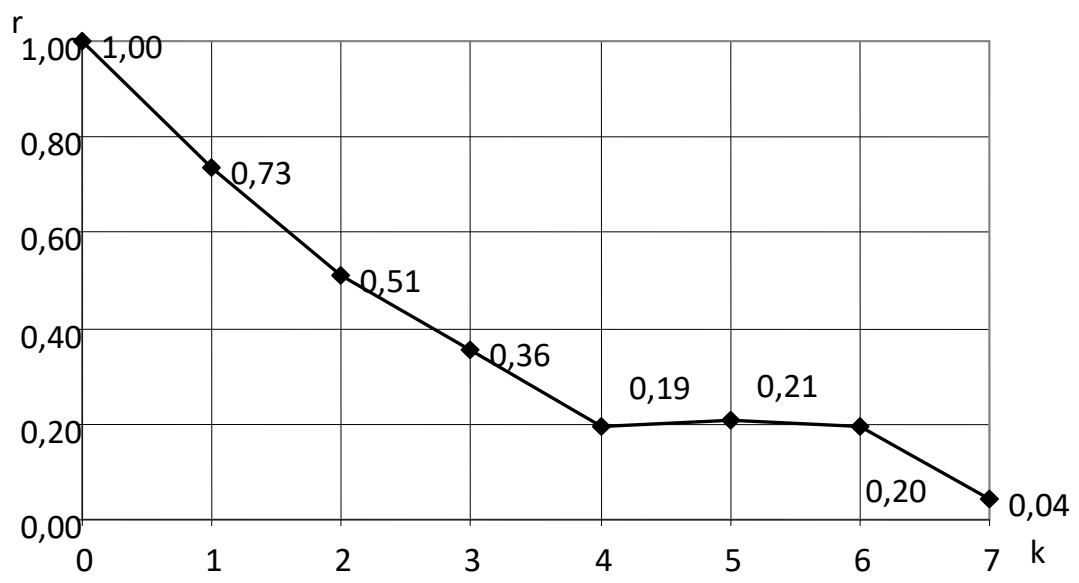

Рис. 4. Вибіркова автокоремяційна функція вмісту заліза магнітного в забої екскаватору № 23

В табл. 2 наведено значення вибіркових нормованих спектрів, що розраховані за формулою (10) на основі даних табл. 2.

Значення вибіркових нормованих спектрів

Таблиця 2

\begin{tabular}{|c|c|c|c|}
\hline $\begin{array}{c}\text { № } \\
\text { екскаватора }\end{array}$ & 93 & 56 & 23 \\
\hline 0 & 6,76 & 19,31 & 10,97 \\
\hline 0,1 & 4,548 & 2,62 & 2,41 \\
\hline 0,2 & 1,167 & 0,03 & 1,29 \\
\hline 0,3 & 0,032 & 0,45 & 0,38 \\
\hline 0,4 & 0,853 & 0,00 & 0,32 \\
\hline 0,5 & 0,04 & 0,00 & 0,23 \\
\hline
\end{tabular}

Аналіз вибіркових нормованих спектрів, який буде виконано далі, дозволить зробити висновки про те, на яких частотах і як концентрується дисперсія рядів, що досліджуються.
На рис. 5, 6 та 7 наведено графіки вибіркових нормованих спектрів, розрахованих згідно з даними табл. 2.

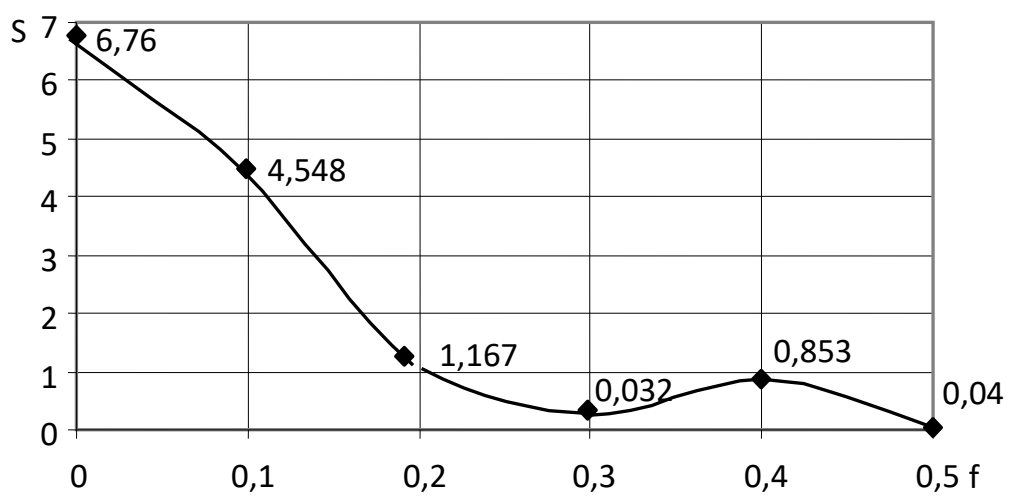

Рис. 5. Вибірковий нормований спектр вмісту заміза магнітного в забої екскаватору № 93 
Графічний аналіз вибіркових нормованих спектрів, що представлені на рис. 5, 6 та 7, дозволяє зробити висновок, що дисперсія досліджуваних рядів концентрується в основному на низьких частотах, а саме - від 0 до 0,3 .
В подальшому, при використанні даної методики, зона концентрація дисперсії приймається як найбільш доцільна для аналізу.

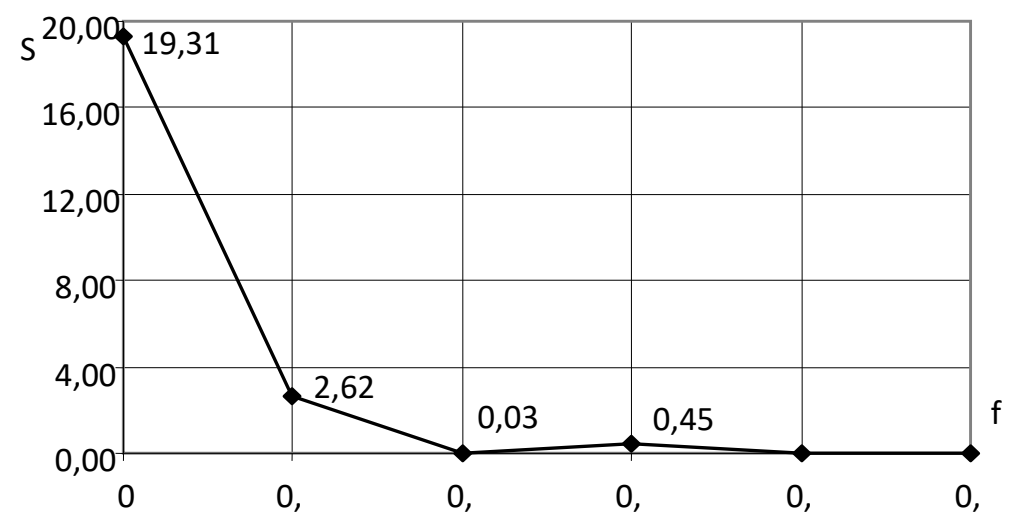

Рис. 6. Вибірковий нормований спектр вмісту заміза магнітного в забої екскаватору № 56

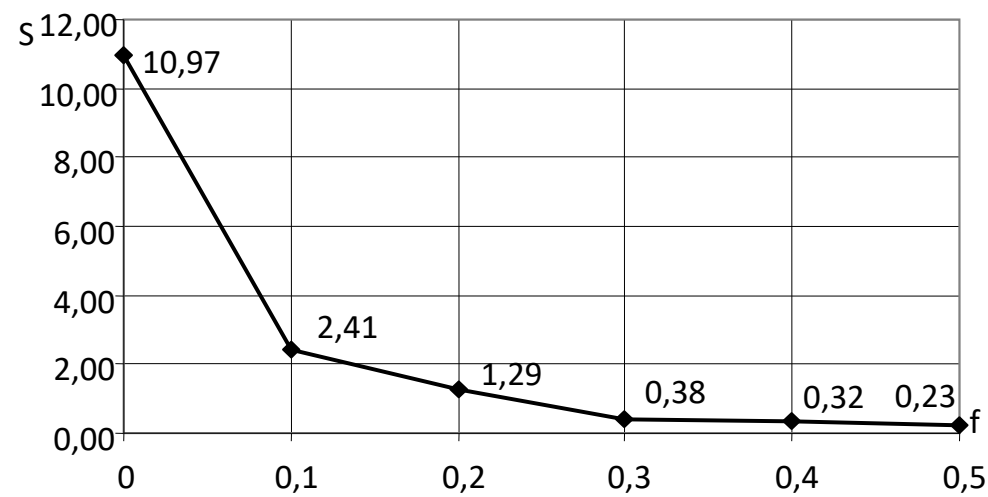

Рис. 7. Вибірковий нормований спектр вмісту заміза магнітного в забої екскаватору № 23

Таким чином, для можливості виділення частот, що пов'язані зі зміною вмісту заліза в руді, досить вибрати частоту $f=0,3 / \Delta$, або позначити період

$$
T=\frac{10 \cdot \Delta}{3}
$$

Спираючись на те, що згідно 3 існуючою дискретністю вимірюванням у забоях вмісту заліза магнітного в руді, які здійснюються з інтервалом 12 годин, отримуємо можливість математично
Отримане значення періоду опробування якості у видобувних отримання інформації про вміст корисного компонента в забоях кар'єру у наступному вигляді: період опробування забоїв, що дозволить розрізняти максимальні частоти зміни вмісту корисного компоненту:

$$
T=\frac{10 \cdot 12}{3}=40 \text { годин }
$$$$
\text { опробування якості у видобувних }
$$

забоях (11) вказує на можливість збільшення існуючого періоду в більше 
ніж у три рази без втрати необхідної інформації про динаміку зміни вмісту корисного компонента.

Наявність такої інформації дозволить формувати загальний інтегрований рудний вантажопотік кар'єру 3 потрібними показниками якості, що вплине на показники прибутку гірничовидобувного підприємства [5].

Слід зазначити, що з точки зору математичної статистики, чим за більший період буде застосовані дані про розподіл якості у забоях, тим вірогіднішим буде розрахунок періоду вимірювання. Враховуючи стохастичний характер розподілу якості в межах родовища, доцільно проводити уточнюючи розрахунки, тому що 3 підвищенням коливань вмісту корисного компоненту в забоях період опробування буде скорочуватися.

Дану методику може бути застосовано на всіх залізорудних підприємствах, де $\epsilon$ відповідний статистичний матеріал про вміст

\section{References}

Byzov, V.F., Vilkul, Ju.G., Maksimov, I.I. (1982). Ob usrednenii kachestva rud pri ob\#edinenii

Metallurgicheskaja promyshlennost', 2, 64-65. gruzopotokov. promyshlennost, 2, 64-65.

Babij, E.V., Sinenko, M.A. (2010). O kachestve rudnogo potoka pri tehnologi predobogashhenija rudy $\mathrm{v}$ kar'ere. Visnyk Kryvorizkoho natsionalnoho universytetu, 25, 3-8. корисного компонента у видобувних забоях за певний період вимірювань.

\section{ВИСНОВКИ}

1. Запропонована

методика обгрунтування дискретності опробування якісних характеристик залізорудної сировини дозволяє обгрунтовано визначити період проведення вимірів вмісту корисного компоненту у забоях.

2. Розрахунками на прикладі кар'єру № 3 Гірничого департаменту ПАТ «АрселорМіттал Кривий Ріг» доведено можливість збільшення періоду опробування без втрати необхідної інформації про вміст заліза та без зниження якісних характеристик сформованого фінального рудопотоку.

3. Зміна періоду опробування у бік збільшення дозволить знизити витрати підприємства, зменшуючи кількість рейсів фахівців відділу технічного контролю на опробування забоїв кар'єру.

Rodionov, I.B. (2011). Teorija i sistemnyj analiz, Retrived from http://eidos.ru/journal/1998/0781.htm.

Gmurman, V.E. (1975). Rukovodstvo k resheniju zadach po teorii verojatnostej i matematicheskoj statistike. Moskva: Vysshaja shkola

Azarjan, V.A. (2015). Issledovanie vlijanija kachestva rudopotoka zhelezorudnogo kar'era na pribyl' gornoobogatitel'nogo kombinata. Hirnychyi visnyk, 100, 58-62 